\title{
NOT SO FAST: DOMAIN-GENERAL FACTORS CAN ACCOUNT FOR SELECTIVE DEFICITS IN GRAMMATICAL PROCESSING
}

\author{
Elizabeth Bates \\ Center for Research in Language, 0526 \\ University of California, San Diego \\ La Jolla, CA 92093-0526 \\ bates@crl.ucsd.edu \\ Frederick Dick \\ Center for Research in Language, 0526 \\ University of California, San Diego \\ La Jolla, CA 92093-0526 \\ fdick@crl.ucsd.edu \\ Beverly Wulfeck \\ Dept. of Communicative Disorders \\ San Diego State University \\ San Diego, CA 92182-1518 \\ wulfeck@crl.ucsd.edu
}

Supported by NIDCD 2-R01-DC00216 and NINDS NS22343. Please address correspondence to Frederic Dick, University of California, San Diego, La Jolla, Ca. 92093-0526.

Behavioral and Brain Sciences, 1999, 22(1), 96-97. 


\title{
NOT SO FAST: DOMAIN-GENERAL FACTORS CAN ACCOUNT FOR SELECTIVE DEFICITS IN GRAMMATICAL PROCESSING Elizabeth Bates, Frederick Dick and Beverly Wulfeck
}

\begin{abstract}
Normals display selective deficits in morphology and syntax under adverse processing conditions. Digit loads do not impair processing of passives and object relatives, but do impair processing of grammatical morphemes. Perceptual degradation and temporal compression selectively impair several aspects of grammar, including passives and object relatives. Hence we replicate CW's specific findings but reach opposite conclusions, based on wider evidence.
\end{abstract}

Passives and object relatives are more difficult for agrammatic aphasics to process and interpret than actives and object relatives. CW (Caplan \& Waters, in press) ascribe this well-known fact to deficits in a domain-specific grammatical processor, with a syntaxspecific pool of working-memory resources. They base this conclusion on evidence involving comprehension of a small subset of English syntactic structures, in patients with agrammatic aphasia, patients without receptive agammatism despite working-memory deficits, and young adults stratified by memory span and/or tested under a digit load to simulate deficits in domaingeneral working memory. Against MCJ (Miyake, Carpenter, \& Just, 1994), who simulated receptive agrammatism in normals with speeded visual stimuli, CW do not find specific effects on "hard" sentence types as a function of digit load or memory span. We have replicated CW's results, but we have also replicated those of $\mathrm{MCJ}$, and we believe that $\mathrm{CW}$ have moved too fast in their broad conclusions about the autonomy of grammatical processing. Using a broader range of structures, languages, and patient groups, with controls tested under a broader range of adverse processing conditions, we conclude that specific deficits in grammar can be explained without recourse to a domain-specific resource or processing device. Our interpretation differs from that of MCJ, but it is similar in spirit.

First, the same hierarchy of difficulty (actives, subject relatives > passives, object relatives) has been observed in several languages, in many different populations, including Broca's aphasics, Wernicke's aphasics, anomics without expressive agrammatism, and individuals in the early stages of first- or secondlanguage acquisition. The pattern is not unique to any form of aphasia or to any lesion site.

Second, other facets of receptive agrammatism (deficits in the use of function words and grammatical inflections) have been observed in a broad range of patient populations, and in normals subjected to a broad range of stressors. Published and unpublished studies from our laboratory have simulated selective deficits in morphology (with relative sparing of word order) in college students processing under a digit load, a partial noise mask, low-pass filtering and/or auditory compres- sion. These results hold, in varying degrees (depending on the strength of each information type under normal conditions) in English, Italian and German.

Third (and most relevant to CW's claim), selective deficits in the processing of passives and object clefts have been demonstrated in English college students, but under conditions different from those adopted by CW. Because they failed to demonstrate effects of digit load or working-memory capacity on the above sentence hierarchy, CW conclude that syntactic processing is affected only by deficits within a syntax-specific pool of processing resources, and not by reductions in working memory outside this domain (as claimed by MCJ, based on results with speeded presentation). We have shown that $\mathrm{CW}$ and MCJ are both right: College students tested under a digit load (a task that disrupts computation of subject-verb agreement and other inflectional phenomena in our laboratory) are unimpaired in their ability to process passives and object clefts (replicating $\mathrm{CW}$ ), but (2) students tested under perceptual degradation and/or temporal compression are selectively impaired on precisely those sentence types (replicating MCJ, in the auditory modality). Further-more, students tested with both compression and noise produced super-additive results, greater than we would expect by adding separate effects of compression and degradation alone, and strikingly similar to results for aphasic patients in the same paradigm (similar error rates, and similar patterns of individual variation in a cluster analysis).

We conclude that the specific challenges posed by passive and object relatives are not unique to a single aphasia type, and can be explained without recourse to syntax-specific mechanisms or to damage involving specific lesion sites. We propose a domain-general account of the specific difficulties posed by lowfrequency syntactic structures that differs from the working-memory proposal of $\mathrm{MCJ}$, reflecting the effects of structural frequency on encoding (activation of stimuli) rather than memory (maintenance of stimuli in working memory). Grammatical morphemes are vulnerable to stressors of either type (including digits); low-frequency word orders are vulnerable at encoding, but form solid memory traces that are mnemonically robust if they make it over the encoding threshold. This 
would explain why patients with working-memory deficits do not show the predicted pattern, but it does not permit $\mathrm{CW}$ to leap to a much stronger conclusion, i.e., that syntactic deficits reflect damage to an autonomous processor, independent from the processing resources used by other cognitive systems. Our account makes differential predictions for the fate of complex sentence types under stress in cross-linguistic comparisons, results that are supported by preliminary findings for German and Italian.

\section{REFERENCES}

Bates, E., Devescovi, A., Dronkers, N., Pizzamiglio, L., Wulfeck, B., Hernandez, A., Juarez, L., \& Marangolo, P. (1994). Grammatical deficits in patients without agrammatism. Brain and Language, 47, 400-402.

Blackwell, A., \& Bates, E. (1995). Inducing agrammatic profiles in normals. Journal of Cognitive Neuroscience, 7, 228-257.
Caplan, D. \& Waters, G. (in press). Verbal working memory and sentence comprehension. The Behavioral and Brain Sciences.

Dick, F., Bates, E., Wulfeck, B. \& Dronkers, N. (1998). Deficits in the interpretation of complex sentences in aphasic patients in normals under adverse processing conditions. University of California, San Diego, Center for Research in Language.

Kilborn, K. (1991) Selective impairment of grammatical morphology due to induced stress in normal listeners: Implications for aphasia. Brain and Language, 41, 275-288.

Miyake, A., Carpenter, P., \& Just, M. (1994). A capacity approach to syntactic comprehension disorders: Making normal adults perform like aphasic patients. Cognitive Neuropsychology, 11, 671-717.

Naucler, N., Wulfeck, B., \& Bates, E. (1998). A developmental study of complex sentence interpretation abilities (Tech. Rep. CND-9803). University of California, San Diego, Center for Research in Language, Project in Cognitive and Neural Development. 